\title{
A new form of autosomal dominant limb-girdle muscular dystrophy (LGMD1G) with progressive fingers and toes flexion limitation maps to chromosome 4p21
}

Alessandra Starling, Fernando Kok, Maria Rita Passos-Bueno, Mariz Vainzof and Mayana Zatz European Journal of Human Genetics (2005) 13, 264. doi:10.1038/sj.ejhg.5201364

Correction to: European Journal of Human Genetics (2004)

12, 1033-1040. doi: 10.1038/sj.ejhg.5201289
The authors wish to report an error made in the location of the LGMD1G locus. This should be $4 \mathrm{q} 21$ and not 4p21.

\section{Loss of lysosomal association of cystatin B proteins representing progressive myoclonus epilepsy, EPM1, mutations}

Kirsi Alakurtti, Ekkehard Weber, Riitta Rinne, Gerit Theil, Gerrit-Jan de Haan, Dick Lindhout, Paula Salmikangas, Pekka Saukko, Ulla Lahtinen and Anna-Elina Lehesjoki

European Journal of Human Genetics (2005) 13, 264. doi:10.1038/sj.ejhg.5201365

Correction to: European Journal of Human Genetics (2005)

13, 208-215. doi:10.1038/sj.ejhg.5201300
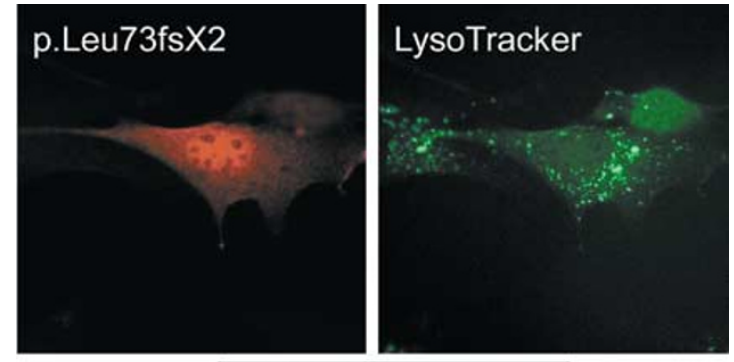

overlay

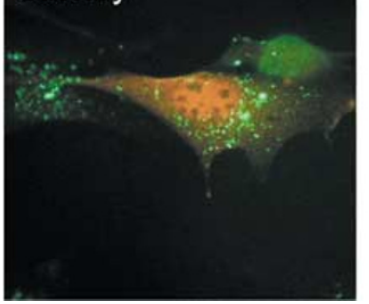

The authors have identified an error in the abovementioned article. The mutation p.Lys73fsX2 should be p.Leu73fsX2 throughout the article. This includes Figure $5 \mathrm{~d}$, the correct version of which is shown here.

Figure 5 Transient expression of CSTB polypeptides representing EPM1-associated mutations in BHK cells. (a) Transiently expressed wild-type CSTB (red) displays a distribution similar to that of the endogenous protein including localization to the nucleus, cytoplasm and lysosomes (visualized with LysoTracker Green). The p.Gly4Arg (b), p.GIn71Pro (c) and p.Leu73fsX2 (d) mutant proteins are detected in the nucleus and cytoplasm, but show no overlap with the LysoTracker and thus no association with lysosomes. The p.Arg68X (e) mutant protein is detected only in the presence of lactacystin, indicating rapid degradation by proteasomes. Immunofluorescence stainings were carried out with the monoclonal (2E7) $(\mathbf{a}-\mathbf{c})$ or polyclonal CSTB antibody (d and e). Even though the epitope recognized by 2E7 was preserved in both truncated mutant proteins, the antibody failed to detect them and a polyclonal CSTB antibody was used instead. 